\title{
Numerical and Experimental Study on Crushing Properties of Hard Coal Using Impacting-Cutting Technique
}

\author{
Qiang Zhang, ${ }^{1,2}$ Cong Wang $\mathbb{D}^{1,2}$ and Ying Tian ${ }^{2}$ \\ ${ }^{1}$ College of Mechanical Engineering, Liaoning Technical University, Fuxin 123000, China \\ ${ }^{2}$ College of Mechanical and Electronic Engineering, Shandong University of Science and Technology, Tsingdao 266590, China
}

Correspondence should be addressed to Cong Wang; 447095012@qq.com

Received 11 November 2021; Revised 9 January 2022; Accepted 17 January 2022; Published 9 February 2022

Academic Editor: Xue-qiu He

Copyright (C) 2022 Qiang Zhang et al. This is an open access article distributed under the Creative Commons Attribution License, which permits unrestricted use, distribution, and reproduction in any medium, provided the original work is properly cited.

The reserves of high-quality coal seams have been greatly reduced in recent years, and the low efficiency of traditional cutting methods in hard coal seams has become a problem for the coal production industry. In order to improve the mining efficiency, an impacting-cutting technique was proposed in this study. A drum modification model with picks impact function was established, and crushing properties of the impacting-cutting drum at f4, f5, and f6 coal hardness were simulated using the discrete element method. The simulation results show that the impacting-cutting drum has higher coal crushing efficiency, lower drum force, and more stable cutting processes than the traditional drum. It shows that hard coal might be effectively reduced by the impactingcutting technique to reduce the difficulty of mining, and reflected the applicability in hard coal seams. Meanwhile, a simplified test device for the impacting-cutting technique was designed. And the actual coal crushing performance was tested. The test results show that the force of the cutting mechanism in the impact mode is lower than that of the nonimpact mode, and the force is more stable. It proves that the impacting-cutting technique has a higher applicability of hard coal seams than the traditional technique.

\section{Introduction}

With the increasing proportion of complex coal seams [1-4], the efficiency of traditional mechanical coal mining methods is getting lower. Since most of the complex coal seams are harder, it is difficult to achieve good results by increasing the size or power of the cutting mechanism under such conditions. This is because the external load imposed by the traditional cutting mechanism is difficult to form a good fracture development inside the hard coal $[5,6]$. Therefore, it is necessary to study a new crushing method for hard coal seams in a more targeted manner in terms of crushing mechanism.

For hard coal seams, there are currently some new coalcrushing technologies, which are classified according to their working principles and can be divided into jet crushing [7-9], jet-assisted mechanical crushing [10-13], special-shaped pick crushing $[14,15]$, and laser crushing $[16,17]$. In recent years, these methods were carried out fruitfully by scholars. Zhao et al. [18] studied the influence of particle water jet parameters on rock impact depth and crushing effect based on the smooth particle hydrodynamics (SPH) method. Li et al. [19] studied the mining efficiency of hydraulic fracturing assisted crushing technology under hard rock and analyzed the stress distribution around crack propagation holes. Chen et al. [20] proposed an advanced premixed Microsoft abrasive coal-water jet technology and studied the impact effect and change law of it. Liu et al. [21] proposed a method with axial vibration and radial cutting technology, and analyzed the mechanical characteristics of the disc cutter in axial vibration and radial cutting of broken coal rock. Starting from the process of laser crushing coal and rock and circulating gas, Yang et al. [22] theoretically analyzed the process of laser crushing coal and rock. Zuo et al. [23] studied the principle of combined laser and mechanical rock crushing, using the CFD-DEM method to carry out fluid-solid coupling analysis, and obtained the law of the influence of strength of high-speed compressed airflow on the effect of cutting migration. 
Obviously, the mining efficiency of the above methods is improved than the traditional technique, but they also have certain limitations from a general perspective. For example, the water jet may increase the viscosity of coal, and the abrasive jet may cause the abrasive particles to be mixed into the coal, which increases the difficulty of subsequent coal washing and coal preparation. The processing cost of a special-shaped pick is higher, and there are higher requirements in its material strength. Laser crushing is difficult to control the energy range, and it may change the properties of coal, which will lead to a physical failure. In response to these problems, an impacting-cutting technique was proposed by the author's research team [24]. The coal cutting characteristics of a single pick with impact function were studied, and the kinematic model of the pick with impact motion was analyzed. In the previous research, a hydraulic control system was formed by the hydraulic impact pick driver set by the ranging arm and the cutting motor to realize the reciprocating impact movement of multiple picks. The impact of picks was used to make coal synchronously precrack, thereby reducing the difficulty of hard coal mining.

Compared with the existing methods, the impacting-cutting technique is combined with the characteristics of jet crushing to reduce the difficulty of cutting by inducing the development of internal cracks in the coal body, and the pick is still used as a carrier for applying external loads to the coal. In this way, the problem of difficulty for coal preparation is avoided. And the requirements for the strength of the pick material are controlled. Meanwhile, the physical properties of the coal are not changed, and approximate continuous discrete shock is more convenient for remote signal control analysis [25-28]. Therefore, from the perspective of production factors, the impacting-cutting technique has considerable advantages.

In this article, the crushing characteristics of hard coal using the impacting-cutting technique were analyzed by the DEM solution. The applicability was explored under hard coal seams, and the traditional drum was compared with it. Moreover, the actual performance of the impacting-cutting technique was tested from the field test, and finally, the results of the DEM solution were verified.

\section{Numerical Simulation}

2.1. Discrete Element Constitutive Relations. In order to facilitate the study of subtle changes of coal in the crushing process, the discrete element algorithm was used to simulate, and the Hertz-Mindlin with the bonding model was used to simulate the constitutive relations of coal. As shown in Figure 1, bonding bond with $O_{c}$ as the center and $R$ as the radius can be generated between two particles under this model.where $R_{A}$ is the radius of particle $A, m ; R_{B}$ is the radius of particle $B, m ; R$ is the radius of bond, $m ; F_{n}$ is the normal force of bond, $N ; F_{t}$ is the tangential force of bond, $N ; M$ is the resultant force of bond, $N ; L$ is the overlapping length of particle $A$ and particle $B, m$.

The force and torque of particles can be borne and transmitted by bonds. These variables will be continuously updated with the external force during the simulation process. The calculation method is

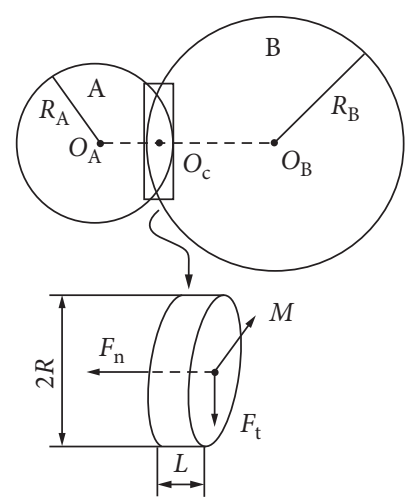

Figure 1: Hertz-Mindlin with bonding model.

$$
\left\{\begin{array}{l}
\delta F_{n}=-v_{n} S_{n} A \delta t, \\
\delta F_{t}=-v_{t} S_{t} A \delta t, \\
\delta T_{n}=-\omega_{n} S_{n} J \delta t, \\
\delta T_{t}=-\omega_{t} S_{t} \frac{J}{2} \delta t, \\
A=\pi R^{2}, \\
J=\frac{\pi R^{4}}{2},
\end{array}\right.
$$

where $F_{n}$ is the normal force of bond, $N$; $F_{t}$ is the tangential force of bond, $N ; T_{n}$ is the normal torque of bond, $\mathrm{N} ; T_{\mathrm{t}}$ is the tangential torque of bond, $\mathrm{N} ; v_{n}$ is the normal velocity of particle, $\mathrm{m} / \mathrm{s} ; v_{t}$ is the tangential velocity of particle, $\mathrm{m} / \mathrm{s} ; \omega_{n}$ is the normal angular velocity of particle, $\mathrm{rad} / \mathrm{s} ; \omega_{t}$ is the tangential angular velocity of particle, $\mathrm{rad} / \mathrm{s} ; S_{n}$ is the normal stiffness of bond, $\mathrm{N} / \mathrm{m}^{3} ; S_{\mathrm{t}}$ is the tangential stiffness of bond, $\mathrm{N} / \mathrm{m}^{3}$; A is the unit contact area, $\mathrm{m}^{2} ; J$ is the polar torque of inertia, $\mathrm{m}^{4} ; R$ is the radius of bond, $m$; and $\delta t$ is time step, $s$.

The bond will be destroyed when the force exceeds the set limit normal stress or limit tangential stress. The basis for the judgment is

$$
\left\{\begin{array}{l}
\sigma_{\max }<\frac{-F_{n}}{A}+\frac{2 T_{n}}{J} R, \\
\tau_{\max }<\frac{-F_{t}}{A}+\frac{T_{t}}{J} R,
\end{array}\right.
$$

where $\sigma_{\max }$ is the maximum normal stress of bond, $\mathrm{Pa} ; \tau_{\max }$ is the maximum tangential stress of bond, Pa.

It can be seen from (1) that the strength of the bond can be expressed as the hardness of coal. Moreover, it can be seen from (2) that the destruction characteristics of the bond can be expressed as the crushing characteristics of coal. Therefore, the Hertz-Mindlin with the bonding model is feasible for analyzing the crushing characteristics of hard coal seam. 
2.2. Discrete Element Solution. The essence of discrete element simulation is to continuously calculate the motion state and force state of the particle element at each moment based on constitutive relations. The time step is set to $\Delta t$. For a particle, the second-order Taylor series of its displacement and velocity is

$$
\left\{\begin{array}{l}
u(t+\Delta t) \approx 2 u(t)-u(t-\Delta t)+\frac{1}{m} F[u(t)] \Delta t^{2}, \\
v(t) \approx \frac{1}{2 \Delta t}[u(t+\Delta t)-u(t-\Delta t)],
\end{array}\right.
$$

where $u(t)$ is the total displacement of particle over time, $m$; $v(t)$ is the velocity of particle over time, $\mathrm{m} / \mathrm{s} ; m_{i}$ is the particle mass, $\mathrm{kg} ; F[u(t)]$ is the force of particle during displacement, $N$.

It is assumed that the force between particles does not change within the time step $\Delta t$. According to Newton's law of motion, the equation of motion of particles can be obtained as

$$
\left\{\begin{array}{l}
F(t)+m_{i} g-\beta_{g} v(t)=m_{i} \frac{\Delta v}{\Delta t}, \\
T(t)-\beta_{g} \omega(t)=I \frac{\Delta \omega}{\Delta t},
\end{array}\right.
$$

where $F(t)$ is the resultant force of particle at moment $t, N ; \beta_{g}$ is the damping coefficient; $T(t)$ is the torque of particle, $N \cdot \mathrm{m}$; $\omega(t)$ is the angular velocity of particle at moment $t, \mathrm{rad} / \mathrm{s}$; I is the inertia moment of particle at moment $t, \mathrm{~kg} \cdot \mathrm{m}^{2}$.

So the velocity iteration formula is

$$
\left\{\begin{array}{l}
v(t)=v(t-\Delta t) \frac{m_{i} / \Delta t-\beta_{g} / 2}{m_{i} / \Delta t+\beta_{g} / 2}+\frac{F(t)+m_{i} g}{m_{i} / \Delta t+\beta_{g} / 2}, \\
\omega(t)=\omega(t-\Delta t) \frac{I / \Delta t-\beta_{g} / 2}{I / \Delta t+\beta_{g} / 2}+\frac{T(t)}{I / \Delta t+\beta_{g} / 2} .
\end{array}\right.
$$

According to the speed calculated by (5), the force of bond can be updated by (5). And the bond state is judged by (2). This method finally forms the discrete element solution basis used in this study.

2.3. Drum Model with Impacting-Cutting Technique. The design principle of the impacting-cutting technique is that the interior of a pick seat is modified by a piston hydraulic cylinder. As shown in Figure 2, by nesting the pick in the piston, the pick can be driven by the piston to make an impact movement under the action of hydraulic pressure.

In order to apply the impacting-cutting technique to a shearer drum, it is necessary to solve the problem of oil supply of each pick, the problem of the oil supply power, and the installation of the external oil pipe. In response to these problems, a drum structure with the impacting-cutting technique was proposed. As shown in Figures 3 and 4, the ranging arm is equipped with a drive. The oil in the hydraulic

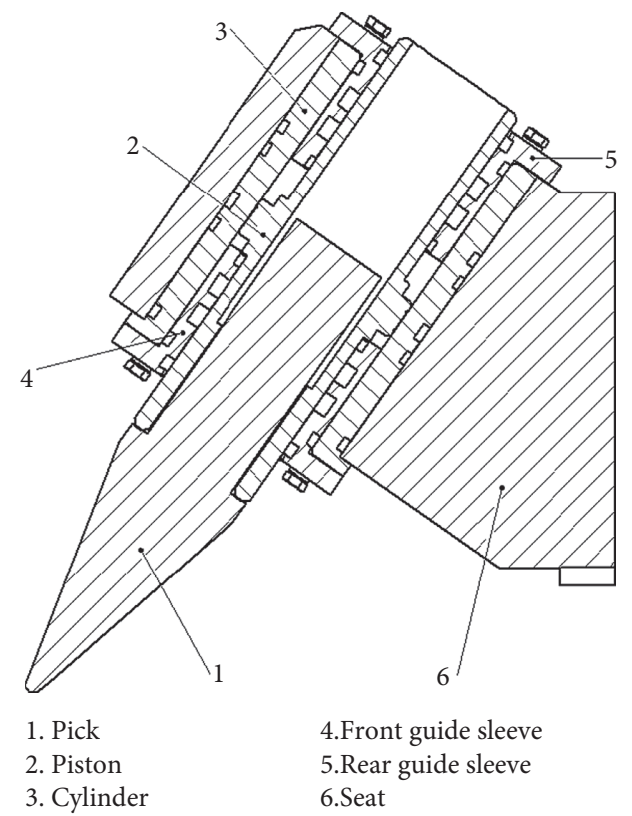

FIGURE 2: Structure of pick using impacting-cutting technique.

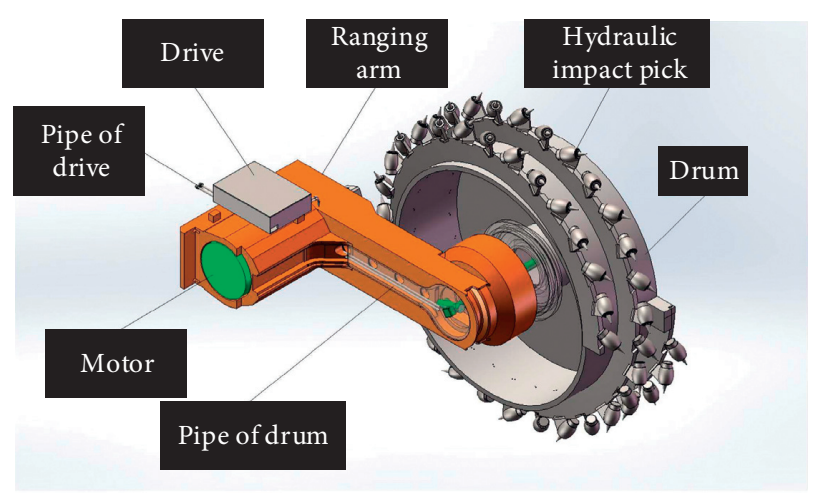

FIgURE 3: Structure of drum using impacting-cutting technique.

tank of shearer is transported to the drum and the picks by the drive through pipes in turn. The reciprocating impact motions of picks are realized by the drive's control of the oil delivery direction [24].

2.4. Discrete Element Model and Parameter Setting. The simulation scheme in this paper was to study the coal crushing characteristics of the impacting-cutting technique drum and the traditional drum at f4, f5, and f6 hardness, respectively. In order to facilitate the study, the coal model assumed that a free surface with a similar shape to the outer envelope surface of drum had been cut. As shown in Figure 5(a), the size of the coal seam model is $1400 \mathrm{~mm} \times 900 \mathrm{~mm} \times 2000 \mathrm{~mm}$, and the particle radius of $20 \mathrm{~mm}$ is set to fill it, as shown in Figure 5(b).

The material parameters and bonding parameters of the coal seam model can be set according to the research of Zhang et al. [25]. Due to the difference in particle size, the bonding radius is different, and the bonding stiffness should be recalculated. The calculation method is 


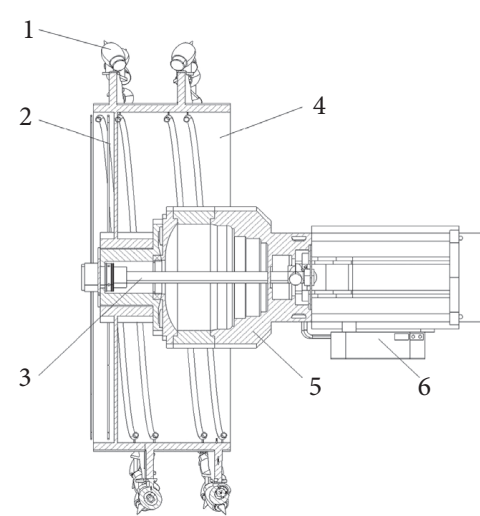

1. Impacting-cutting pick

2. Pipe of picks

3. Pipe of drum 4.Drum

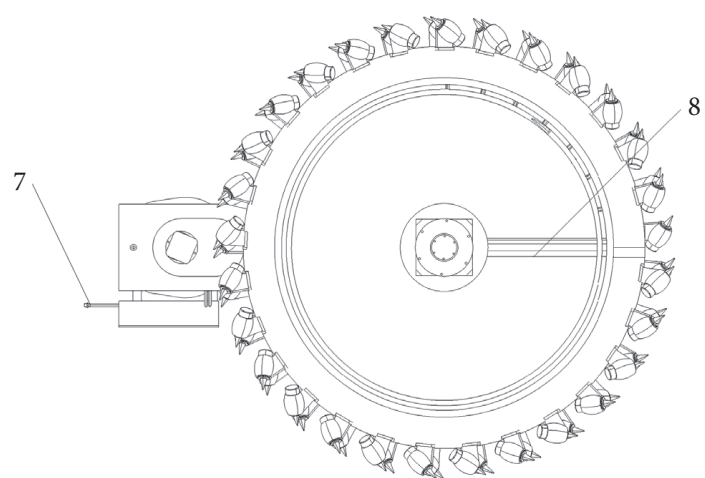

5.Ranging arm

6.Drive

7.Pipe of drive

8.Pipe of drum

FIGURE 4: Distribution of pipes and interior structure of drum.

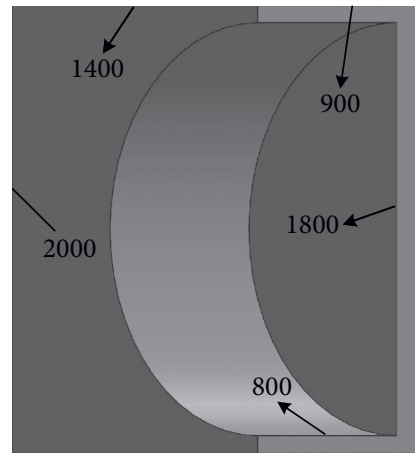

(a)

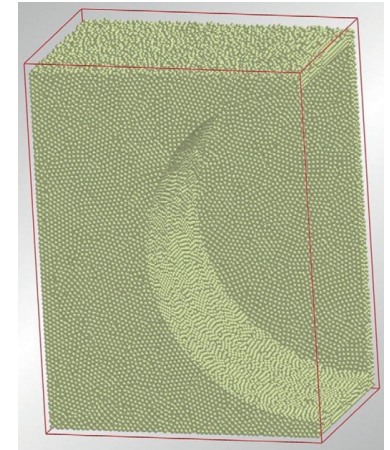

(b)

Figure 5: Coal seam model. (a) Size. (b) Particle filling model.

$$
\left\{\begin{array}{l}
S_{n}=\frac{E}{l}, \\
S_{t}=\frac{G}{l},
\end{array}\right.
$$

where $S_{n}$ is the normal stiffness of bond, $\mathrm{N} / \mathrm{m}^{3} ; S_{t}$ is the tangential stiffness of bond, $\mathrm{N} / \mathrm{m}^{3} ; E$ is the elastic modulus, $\mathrm{Pa} ; G$ is the shear modulus, $\mathrm{Pa}$; and $l$ is the particle spacing, $m$.

Therefore, the material parameters and bonding parameters of the coal model are as shown in Table 1.

Regarding the drum model, the complicated drum structure shown in Figure 3 may cause the simulation accuracy to decrease. For this reason, pipe distribution inside the drum and the hydraulic structure inside the picks were ignored. As shown in Figure 6, a simplified drum model is established.

In the setting of motion parameters, the drum speed was $30 \mathrm{r} / \mathrm{min}$, the traction speed was $10 \mathrm{~m} / \mathrm{min}$, the impact frequency of the pick was $4 \mathrm{~Hz}$, the impact stroke was $10 \mathrm{~mm}$, and the impact strength was $25 \mathrm{MPa}$. In order to realize the impact motions of the picks, the impact strength needs to be converted into acceleration for characterization. The calculation method is

$$
\left\{\begin{array}{l}
F=\mathrm{PS}, \\
a=\frac{F}{m}, \\
t=\sqrt{\frac{2 l_{\mathrm{max}}}{a}},
\end{array}\right.
$$

where $F$ is the impact force, $N ; P$ is the impact strength, $\mathrm{Pa} ; S$ is the surface area of pick tip, $N$; $a$ is the pick acceleration, $\mathrm{m} /$ $\mathrm{s}^{2} ; m$ is the mass of pick, kg; $t$ is the time, $s$; and $l_{\max }$ is the maximum impact stroke of pick, $m$.

According to the pick model shown in Figure 7, it is known that the pick mass $m$ is $2.15 \mathrm{~kg}$. The pick tip diameter is $0.006 \mathrm{~m}$. So, the surface area of pick tip $\mathrm{S}$ is $5.655 \times 10^{-5} \mathrm{~m}^{2}$, and the acceleration a is calculated to be about $685.45 \mathrm{~m} / \mathrm{s}^{2}$, and the time $t$ is about $0.0054 \mathrm{~s}$.

In addition, the impact frequency of the picks was $4 \mathrm{~Hz}$. The picks should be adjusted once every 0.25 s to reimpact. The impact motion time and reset motion time were both 
TABLE 1: Material parameters and bonding parameters under different hardnesses.

\begin{tabular}{lccc}
\hline Hardness & $\mathrm{f} 4$ & $\mathrm{f} 5$ & $\mathrm{f}$ \\
\hline Poisson's ratio & 0.15 & 0.17 & 0.22 \\
Shear modulus $(\mathrm{Pa})$ & $9.56 \times 10^{8}$ & $1.62 \times 10^{9}$ & $1.72 \times 10^{9}$ \\
Density $\left(\mathrm{kg} / \mathrm{m}^{3}\right)$ & 1420 & 0.45 & 1420 \\
Coefficient of restitution & 0.45 & 0.48 & 0.45 \\
Coefficient of static friction & 0.48 & 0.18 & 0.48 \\
Coefficient of rolling friction & 0.18 & $9.5 \times 10^{10}$ & 0.18 \\
Normal stiffness per unit area $\left(\mathrm{N} / \mathrm{m}^{3}\right)$ & $5.5 \times 10^{10}$ & $4.05 \times 10^{10}$ & $1.05 \times 10^{11}$ \\
Shear stiffness per unit area $\left(\mathrm{N} / \mathrm{m}^{3}\right)$ & $2.39 \times 10^{10}$ & $5 \times 10^{7}$ & $4.3 \times 10^{10}$ \\
Critical normal stress $(\mathrm{Pa})$ & $4 \times 10^{7}$ & $2 \times 10^{7}$ & $6 \times 10^{7}$ \\
Critical shear stress $(\mathrm{Pa})$ & $1.6 \times 10^{7}$ & 0.02 & $2.4 \times 10^{7}$ \\
Bonded disk radius $(\mathrm{m})$ & 0.02 & 0.02 \\
\hline
\end{tabular}

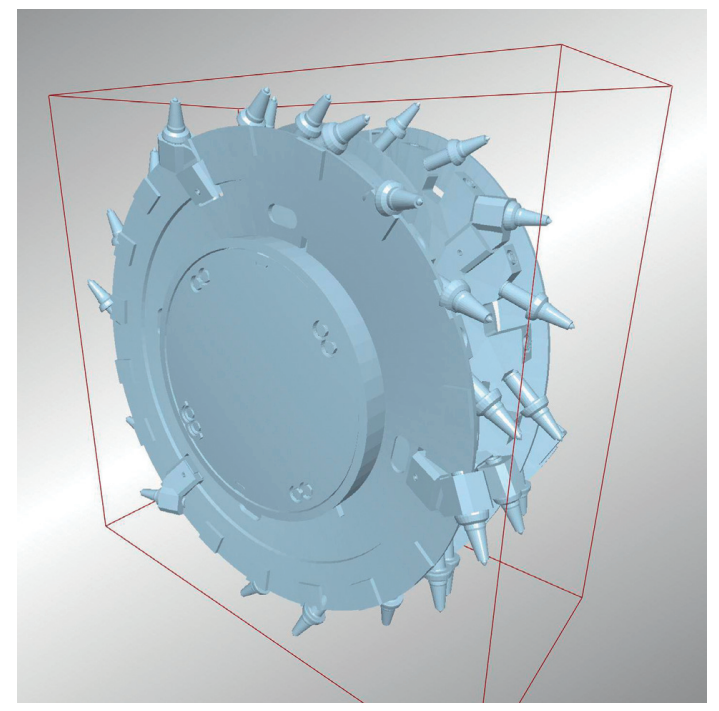

FIgURE 6: Simplified drum model.

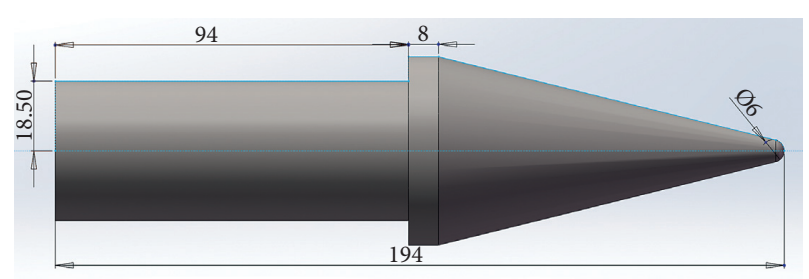

Figure 7: Size of pick model.

$0.0054 \mathrm{~s}$ so that the picks impact motion can be controlled, as shown in Figure 8.

For the motion control of the traditional drum model, it considered the rotation and traction motion of the drum, that is, the impact parameter settings of the picks on the basis of the existing drum model was deleted. The relative simulation time step was set to $20 \%$. Because of the drum speed was $30 \mathrm{r} / \mathrm{min}$ and it took $2 \mathrm{~s}$ to rotate one circle, the total simulation time was set to $2 \mathrm{~s}$. And the discrete element model is established, as shown in Figure 9.

\section{Results and Analysis}

3.1. Coal Crushing Efficiency. The definition of coal crushing efficiency in actual engineering refers to the amount of coal mined per unit time, such as daily mining volume and annual mining volume. Due to the limited simulation time, it was not appropriate to convert to daily mining volume, and the average coal crushing per second during the course of one revolution of the drum was analyzed based on the simulation results.

It was known that the total particle number of the coal model was 175,640 . The number of remaining particles under each scheme was counted, as shown in Table 2. The number of average crushing particles of the impactingcutting drum is higher than that of the traditional drum.

In order to the differences that were more obvious, coal crushing efficiency $\eta$ based on the simulation results was proposed in this study. Idealized coal crushing volume of the drum per second was assumed to be $V_{1}$, the overall volume of the coal model was $V_{2}$, the number of idealized average crushing particles was $a_{1}$, and the total number of coal model particles was $a_{2}$. The calculation method for the number of idealized average crushing particles is

$$
a_{1}=\frac{a_{2} V_{1}}{V_{2}} \text {. }
$$

It was known that the total number of coal model particles $a_{2}$ was 175640 , the idealized coal crushing volume of the drum per second $V_{1}$ was $0.1029 \mathrm{~m}^{3}$, and the overall volume of the coal model $V_{2}$ was $7.15 \mathrm{~m}^{3}$. So, the number of idealized average crushing particles $a_{1}$ was 2,528. Coal crushing efficiency $\eta$ under each scheme was obtained by the ratio of the number of average crushing particles to the idealized number of it. As shown in Table 3, the coal crushing efficiency of the impacting-cutting technique under each scheme has been greatly improved compared with the traditional technique, with a maximum difference of $13 \%$. The increase in the hardness of coal and the greater difference between the two techniques indicate that the impacting-cutting technique may reduce the difficulty of mining hard coal seams.

3.2. Drum Load. The force data during the drum-cutting process for each scheme were counted. As shown in Figure 10, on the one hand, the peak forces of the traditional drum are higher than the impacting-cutting drum, and the forces of the traditional drum have large fluctuations. On the other hand, the forces of the impacting-cutting drum shows 


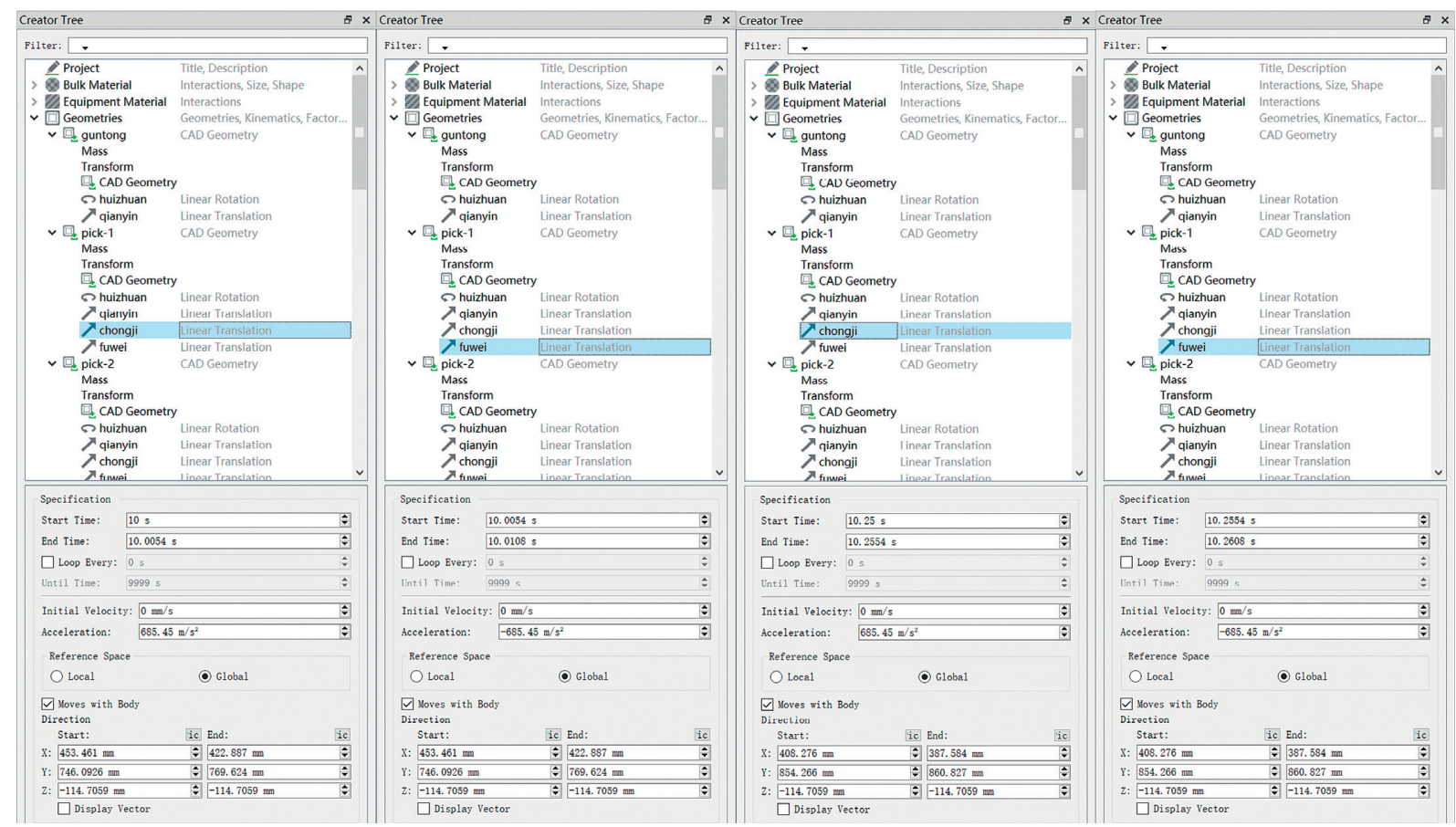

FIGURE 8: Impact motion control of picks.

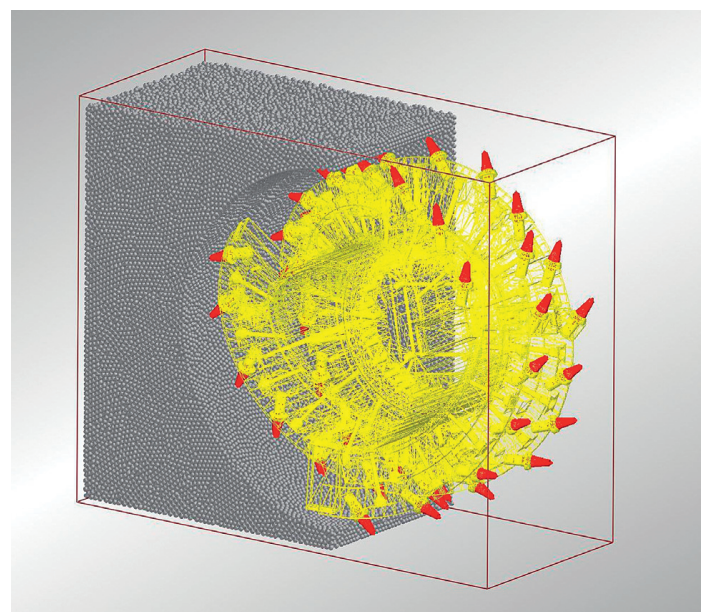

Figure 9: Discrete element model.

TABLe 2: Number of remaining particles and number of average crushing particles for each scheme.

\begin{tabular}{|c|c|c|c|c|c|c|}
\hline Scheme & $\begin{array}{c}\text { Coal hardness of } \mathrm{f} 4 \\
\text { with impacting- } \\
\text { cutting drum }\end{array}$ & $\begin{array}{l}\text { Coal hardness of f5 } \\
\text { with impacting- } \\
\text { cutting drum }\end{array}$ & $\begin{array}{l}\text { Coal hardness of f6 } \\
\text { with impacting- } \\
\text { cutting drum }\end{array}$ & $\begin{array}{l}\text { Coal hardness of } \\
\text { f4 with } \\
\text { traditional drum }\end{array}$ & $\begin{array}{l}\text { Coal hardness of } \\
\text { f5 with } \\
\text { traditional drum }\end{array}$ & $\begin{array}{l}\text { Coal hardness of } \\
\text { f6 with } \\
\text { traditional drum }\end{array}$ \\
\hline $\begin{array}{l}\text { Number of } \\
\text { remaining } \\
\text { particles }\end{array}$ & 171,463 & 171,660 & 171,934 & 171,824 & 172,140 & 172,578 \\
\hline $\begin{array}{l}\text { Number of } \\
\text { average } \\
\text { crushing } \\
\text { particles }\end{array}$ & 2,089 & 1,990 & 1,853 & 1,908 & 1,750 & 1,531 \\
\hline
\end{tabular}

obvious periodic changes. It shows that the impactingcutting technique may reduce the difficulty of crushing hard coal seams. Moreover, the first force peak of the traditional drum appears later. The reason may be that the surface strength of hard coal is higher. It is difficult for the traditional drum to effectively damage the coal in the initial stage. 
TABLE 3: Coal crushing efficiency of each scheme.

\begin{tabular}{|c|c|c|c|c|c|c|}
\hline Scheme & $\begin{array}{l}\text { Coal hardness of } \mathrm{f} 4 \\
\text { with impacting- } \\
\text { cutting drum }\end{array}$ & $\begin{array}{c}\text { Coal hardness of f5 } \\
\text { with impacting- } \\
\text { cutting drum }\end{array}$ & $\begin{array}{c}\text { Coal hardness of f6 } \\
\text { with impacting- } \\
\text { cutting drum }\end{array}$ & $\begin{array}{c}\text { Coal hardness of } \\
\text { f4 with traditional } \\
\text { drum }\end{array}$ & $\begin{array}{c}\text { Coal hardness of } \\
\text { f5 with traditional } \\
\text { drum }\end{array}$ & $\begin{array}{c}\text { Coal hardness of } \\
\text { f6 with traditional } \\
\text { drum }\end{array}$ \\
\hline $\begin{array}{l}\text { Coal crushing } \\
\text { efficiency (\%) }\end{array}$ & 82.63 & 78.71 & 73.30 & 75.47 & 69.22 & 60.56 \\
\hline
\end{tabular}

This further reflects the applicability of the impacting-cutting technique to hard coal.

In order to make the difference of the drum forces under each scheme more obvious, the data in Figure 10 were imported into MATLAB. The average value of the drum force of each scheme was calculated. As shown in Table 4, the average force of the impacting-cutting technique drum under each hardness is lower than that of the traditional drum. And as the hardness increases, the load difference between the two methods is larger, reaching a maximum of nearly $60 \mathrm{kN}$. Therefore, it can be seen from the force of drum that the impacting-cutting technique has a higher applicability of hard coal.

\section{Experimental Set Up}

In the process of designing the impacting-cutting technique test device, due to the impact function of the picks, the pick seats need to be modified, and an additional power source was required to operate the hydraulic circuit. These modifications were complicated to apply to the actual shearer drum. The huge production cost of the drum modification was considered. Meanwhile, in order to avoid the waste of resources caused by the actual unsatisfactory performance, the test device was simplified. The carrier of the impacting-cutting picks was replaced with a cutting disc structure, the size of the cutting mechanism was reduced, and the number of picks was reduced. In the end, a test device for the impacting-cutting machine was formed. As shown in Figure 11, the test device consists of a cutting mechanism, a ranging arm, a double piston hydraulic drive rotary motor, a three plunger hydraulic drive linear motor, a water-cooled cooler, and a hydraulic control unit.

As shown in Figure 12, the cutting mechanism is composed of a hydraulic motor, a high-pressure rotary joint, a cutting disc, and 6 picks. The high-pressure rotary joint, oil pipe, and pick seat are sequentially passed through by the hydraulic oil in the hydraulic motor. The main piston is driven so that the picks are driven by it for impact motions.

As shown in Figure 13, the ranging arm is processed by the articulated shaft to improve the accuracy of the geometric tolerance, and the clearance-free fit is formed. So, the overall stiffness of the ranging arm is improved.

As shown in Figure 14, this is the double piston hydraulic drive rotary motor. Its function is to realize the height adjustment motion of the ranging arm and the rotation motion of the cutting mechanism.

As shown in Figure 15, this is the three plunger hydraulic drive linear motor. Multiple double-acting hydraulic oil cylinders with a constant cross section are controlled by the electric motor using a hydraulic closed circuit so that they are followed by the reciprocating motions of each plunger for impacting and resetting.

As shown in Figure 16, this is the hydraulic control unit of the test device, which is used to control the start and stop state of the picks impact, the lifting motion of the ranging arm, and the rotation motion of the cutting mechanism.

\section{Results and Discussion}

Due to the limited field test conditions, the coal seam hardness of the working face was $\mathrm{f} 3$, and the pick's impact and nonimpact modes was tested together, and the cutting mechanism speed was set to $40 \mathrm{r} / \mathrm{min}$. After operating the test device, the coal body was first cut by the nonimpact mode for 3 minutes and then by the impact mode for 3 minutes. The field test process and coal breaking effect are shown in Figure 17. And the cutting power during the test is counted, as shown in Figure 18.

The data in Figure 18 were converted into the force of the cutting mechanism. The calculation method is

$$
F=\frac{P}{2 \pi n},
$$

where $P$ is the cutting power, $\mathrm{kW}$; and $n$ is the cutting mechanism speed, $\mathrm{r} / \mathrm{min}$.

According to formula (9), the force of the cutting mechanism at each time was obtained. As shown in Table 5, the average force of the cutting mechanism under impact and nonimpact modes is $4473 \mathrm{~N}$ and $5390 \mathrm{~N}$, respectively. The force of the cutting mechanism in the impact mode is reduced by $17.22 \%$ compared with the nonimpact mode, and the force is more stable. The test results are similar to the laws reflected in the simulation results. Therefore, it proves that the impacting-cutting technique has a higher applicability to hard coal seams than the traditional technique.

To verify the cutting performance of the simplified test device under higher coal hardness, a simulation control group was set up in this study. Coal crushing effect with and without picks impact under $\mathrm{f} 5$ hardness was analyzed by EDEM. Meanwhile, in order to speed up the simulation, the structure of the cutting disc was analyzed, and the size of the coal model was reduced. The cutting disc speed was set to $40 \mathrm{r} / \mathrm{min}$ and cut downward for $2 \mathrm{~s}$ in arc direction. The established coal breaking model and the crushing effect of a certain scheme are shown in Figure 19.

The force data of the cutting disc for each scheme were counted. As shown in Figure 20, the force of the cutting disc for two schemes is characterized by an increase in $0 \sim 1 \mathrm{~s}$ and a 


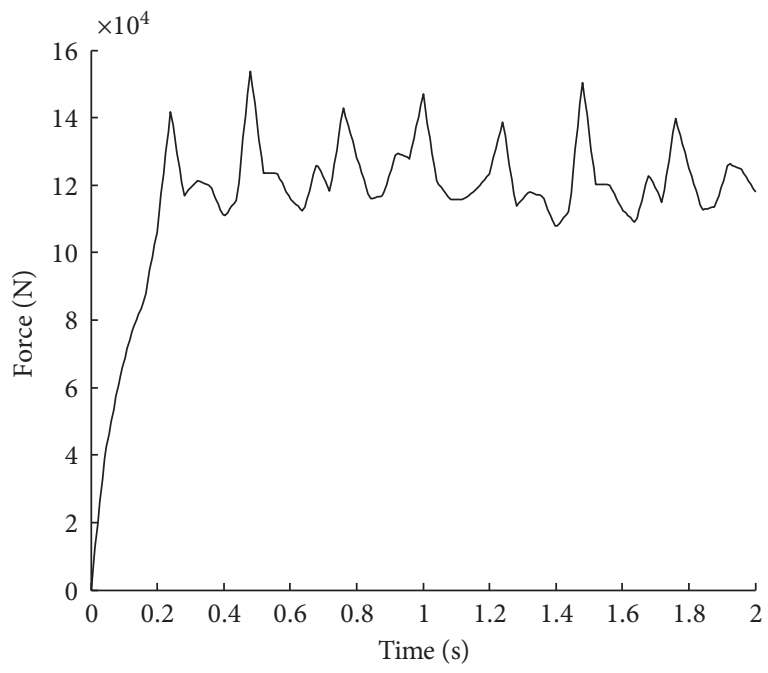

(a)

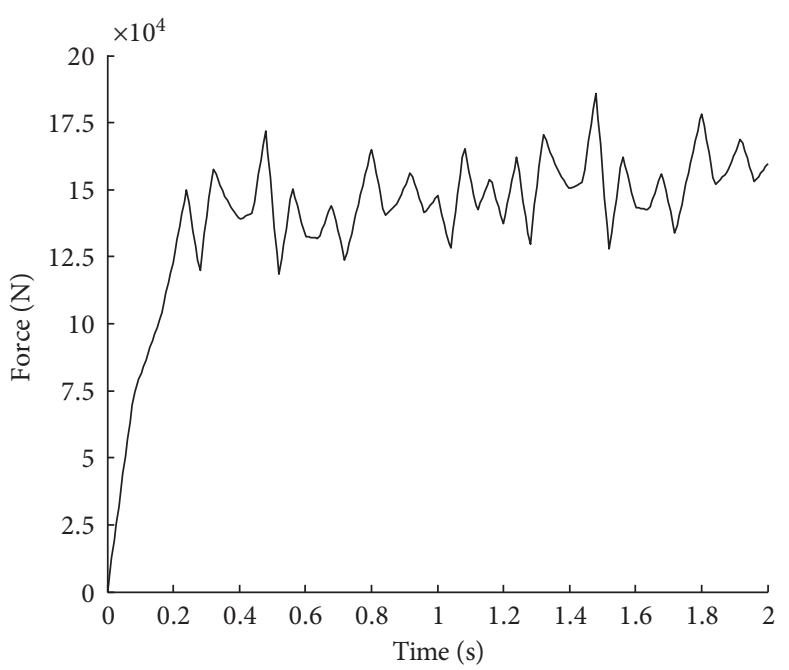

(c)

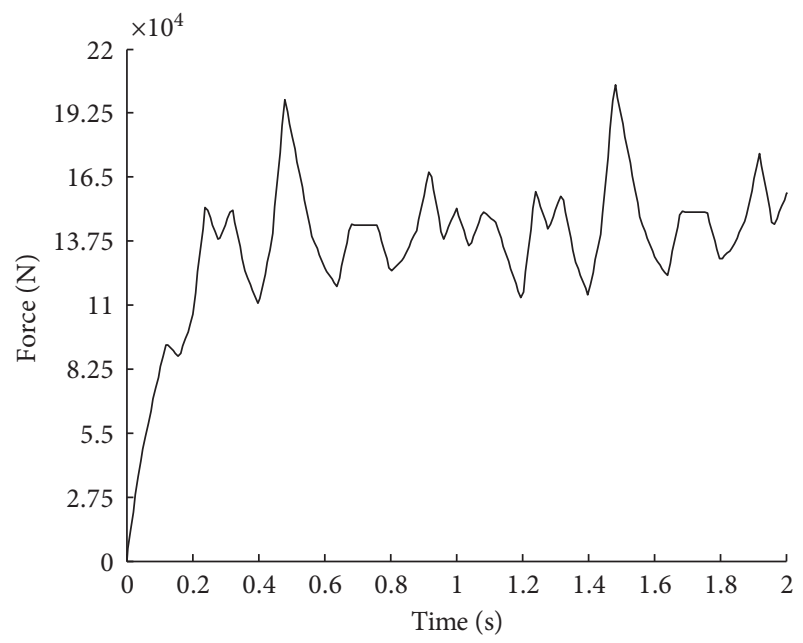

(e)

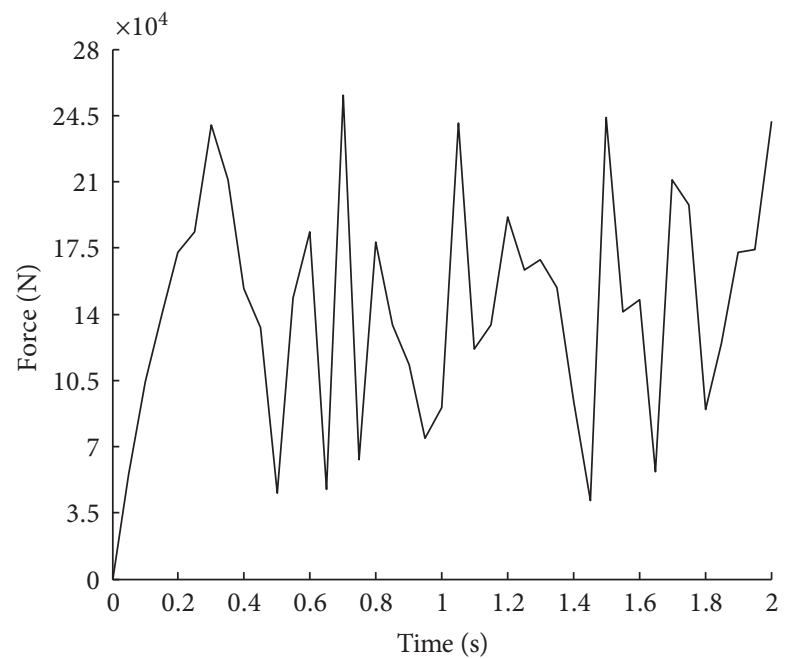

(b)

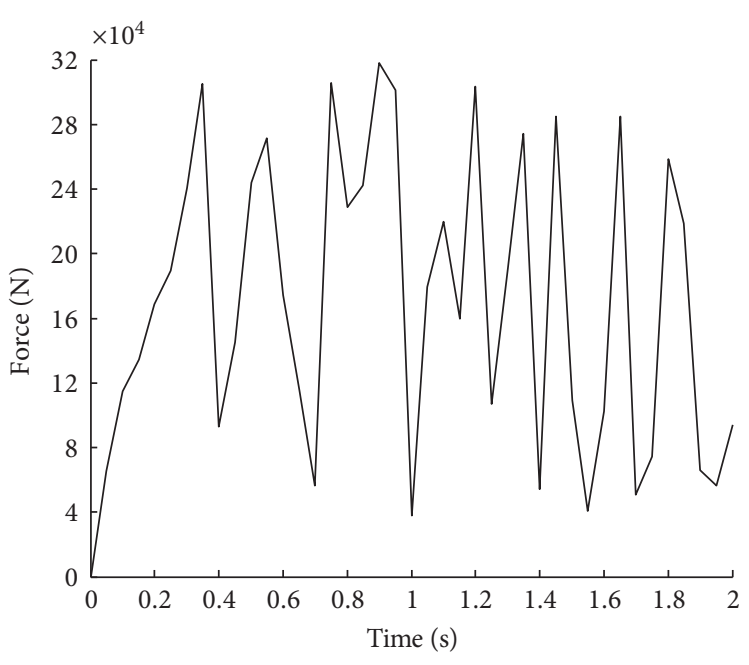

(d)

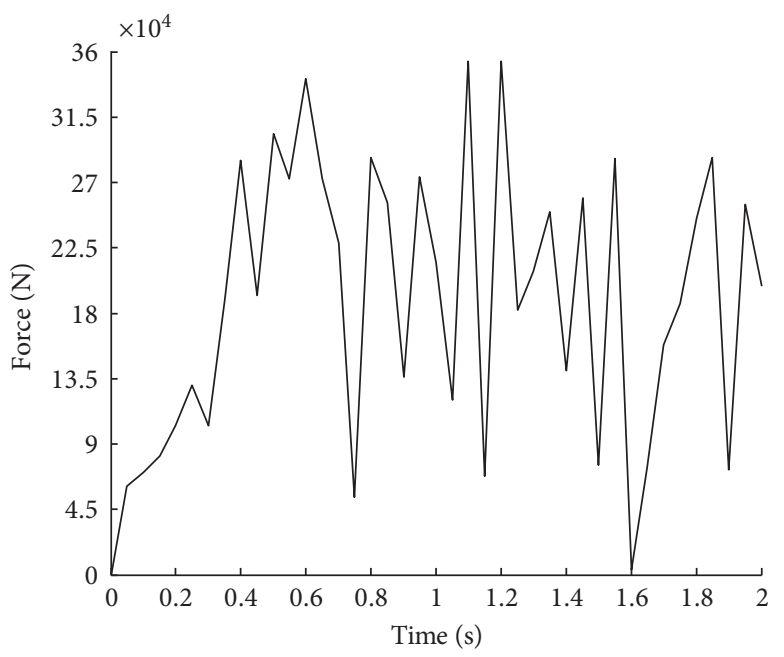

(f)

FIgURE 10: Force of drum for each scheme. (a) Impacting-cutting to f4. (b) Traditional to f4. (c) Impacting-cutting to f5. (d) Traditional to f5. (e) Impacting-cutting to f6. (f) Traditional to f6. 
TABLE 4: Force of each scheme.

\begin{tabular}{lcccccc}
\hline Scheme & $\begin{array}{c}\text { Coal hardness of f4 } \\
\text { with impacting- } \\
\text { cutting drum }\end{array}$ & $\begin{array}{c}\text { Coal hardness of f5 } \\
\text { with impacting- } \\
\text { cutting drum }\end{array}$ & $\begin{array}{c}\text { Coal hardness of f6 } \\
\text { with impacting- } \\
\text { cutting drum }\end{array}$ & $\begin{array}{c}\text { Coal hardness of } \\
\text { f4 with traditional } \\
\text { drum }\end{array}$ & $\begin{array}{c}\text { Coal hardness of } \\
\text { f5 with traditional } \\
\text { drum }\end{array}$ & $\begin{array}{c}\text { Coal hardness of } \\
\text { f6 with traditional } \\
\text { drum }\end{array}$ \\
\hline $\begin{array}{l}\text { Force of } \\
\text { drum } \\
\text { (kN) }\end{array}$ & 116.420 & 129.184 & 140.665 & 154.657 & 182.746 & 201.318 \\
\hline
\end{tabular}

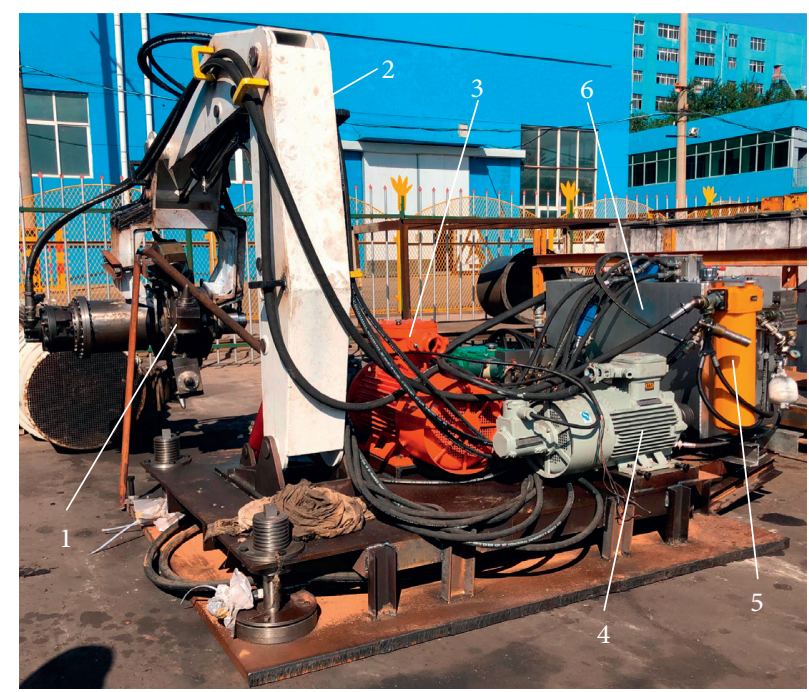

Figure 11: Test device. 1. Cutting mechanism, 2. Ranging arm, 3. Double piston hydraulic drive rotary motor, 4. Three plunger hydraulic drive linear motor, 5. Water-cooled cooler, 6. Hydraulic control unit.

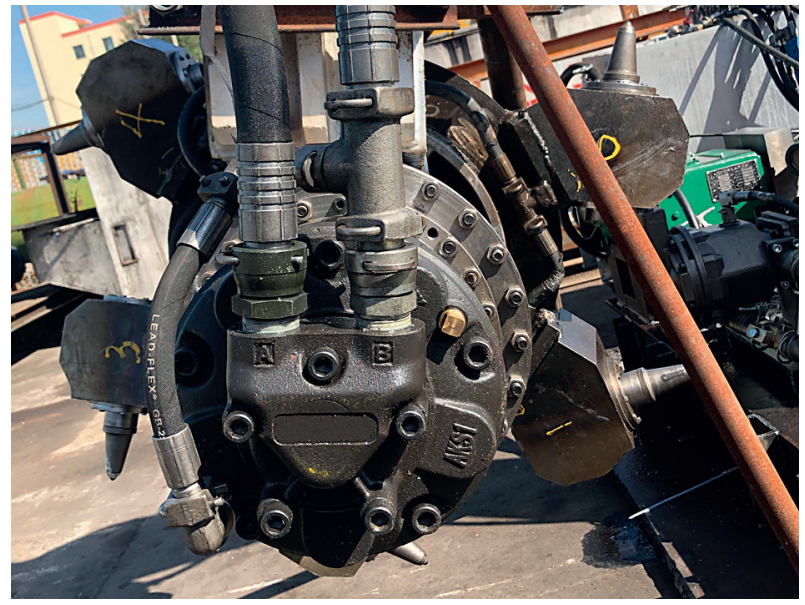

Figure 12: Cutting mechanism.

decrease in 1 2 $\mathrm{s}$. This is because the cutting disc moves in an arc direction, and its force is affected by the cutting depth. In addition, the time when the force of the cutting disc for nonimpact reaches the first peak is later than that of picks impact, but the force value is much larger than that of picks impact. This feature further reflects that the difficulty of hard coal cutting can be reduced by the impacting-cutting

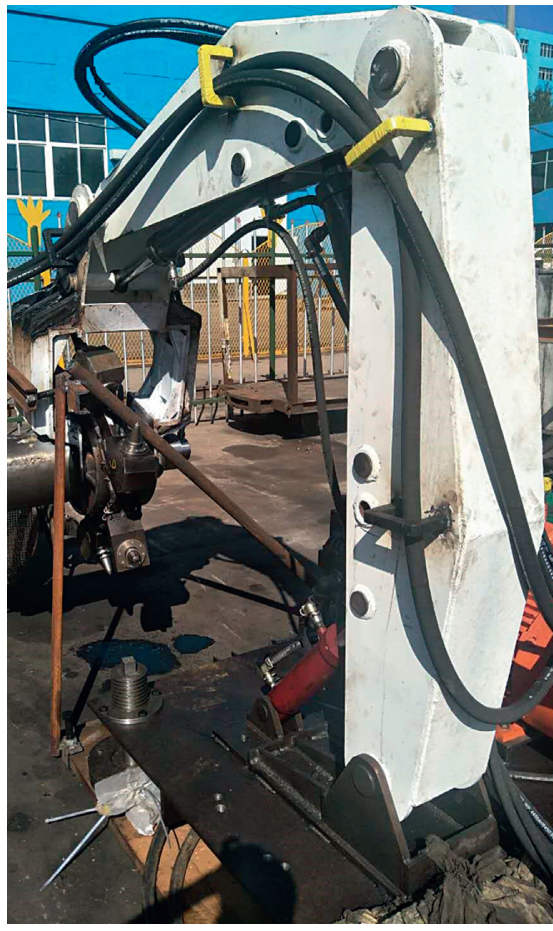

FIGURE 13: Ranging arm. 


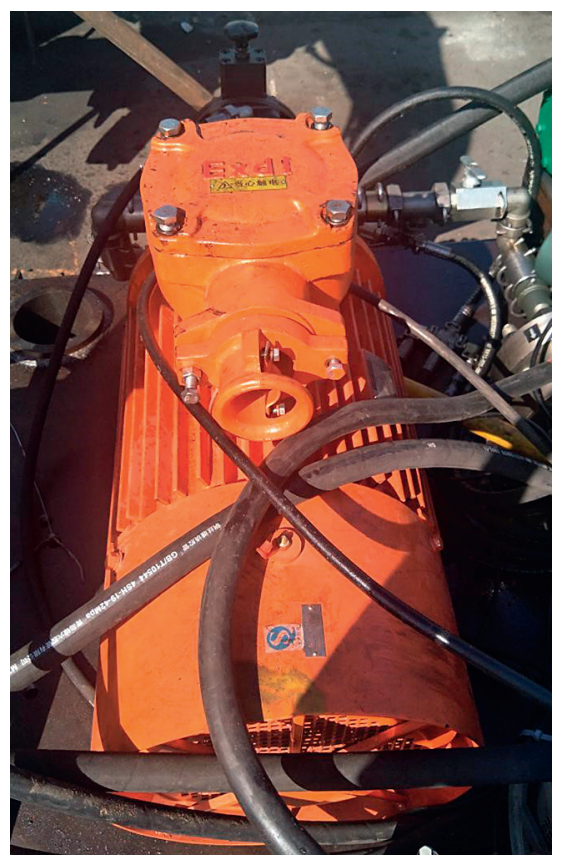

FIGURE 14: Double piston rotary motor.

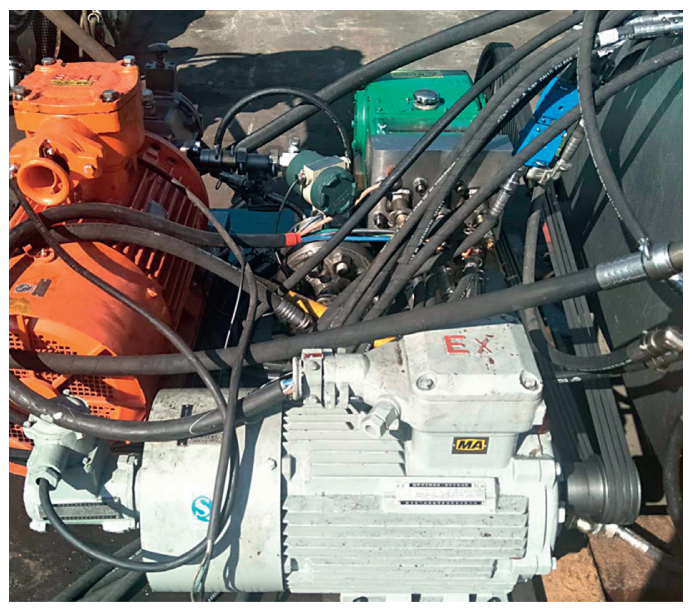

Figure 15: Three plunger linear motor.

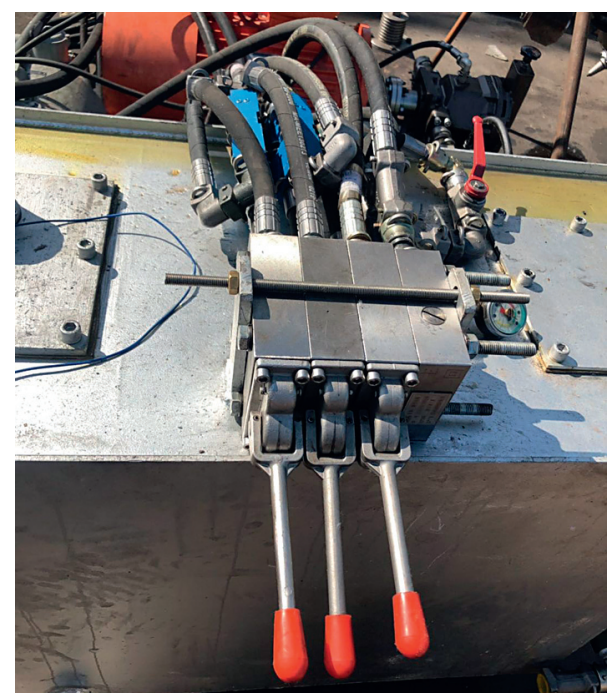

Figure 16: Hydraulic control unit. 


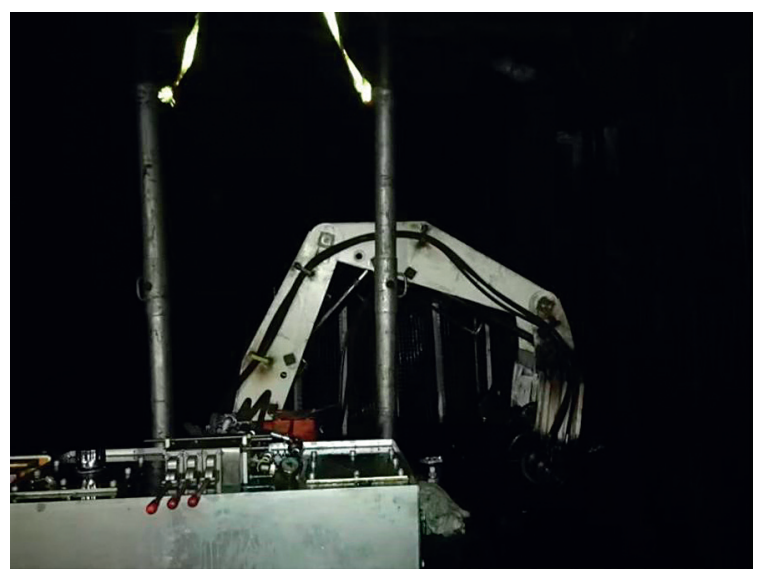

(a)

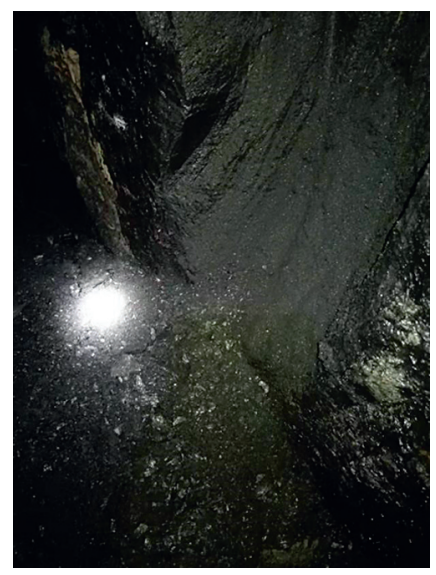

(b)

Figure 17: Coal crushing process of testing. (a) Process. (b) Effect.

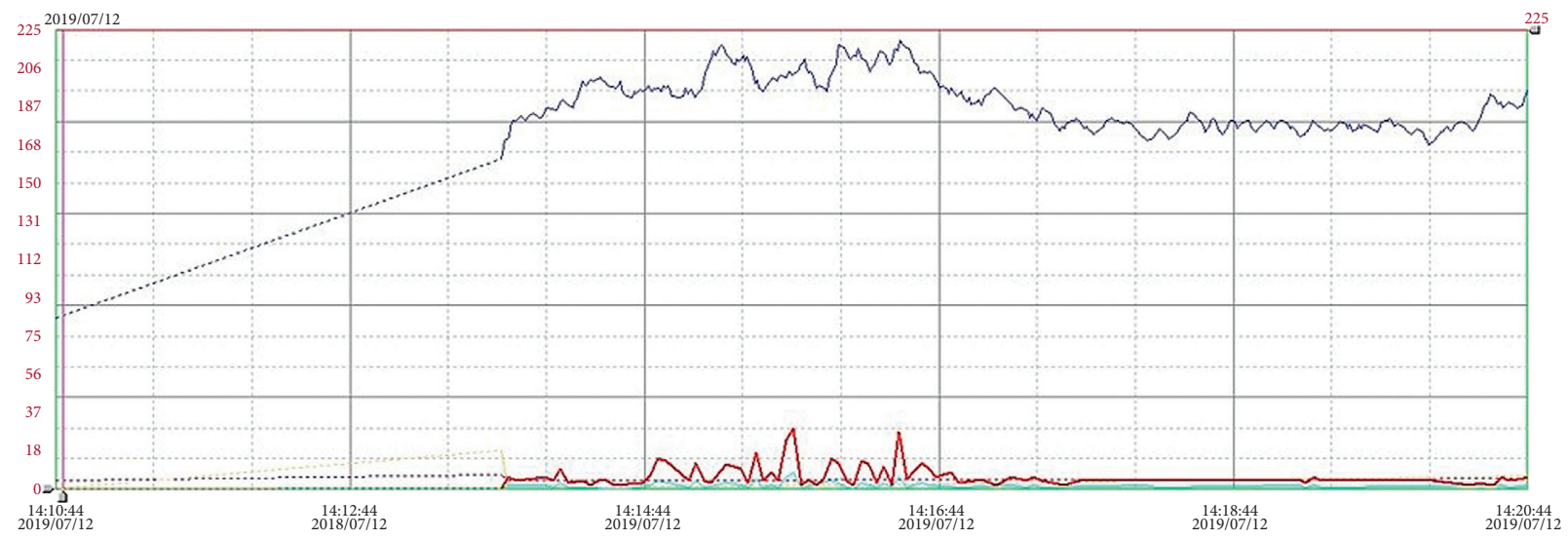

Figure 18: Cutting power.

TABLE 5: Force of the cutting mechanism.

\begin{tabular}{lccccc}
\hline Time & Impact & Cutting resistance/N & Time & Impact & Cutting resistance/N \\
\hline 14:14:00 & No & 4820 & $14: 17: 00$ & Yes & 3871 \\
$14: 14: 20$ & No & 7296 & $14: 17: 20$ & Yes & 4944 \\
$14: 14: 40$ & No & 5188 & $14: 17: 40$ & Yes & 5002 \\
$14: 15: 00$ & No & 5107 & $14: 18: 00$ & Yes & 4286 \\
$14: 15: 20$ & No & 5125 & $14: 18: 20$ & Yes & 4098 \\
$14: 15: 40$ & No & 5356 & $14: 18: 40$ & Yes & 4409 \\
$14: 16: 00$ & No & 5023 & $14: 19: 00$ & Yes & 4875 \\
$14: 16: 20$ & No & 5506 & $14: 19: 20$ & Yes & 4378 \\
$14: 16: 40$ & No & 5174 & $14: 19: 40$ & Yes & 4226 \\
$14: 16: 59$ & No & 5269 & $14: 19: 59$ & Yes & 4641 \\
\hline
\end{tabular}

technique. Meanwhile, the force change of the cutting disc with picks impact is more stable, which is beneficial to prolong the service life of the cutting mechanism.
The average force of the cutting disc for two schemes is calculated by MATLAB, and the average force with and without impact is $11.94 \mathrm{kN}$ and $15.4 \mathrm{kN}$ respectively. The 


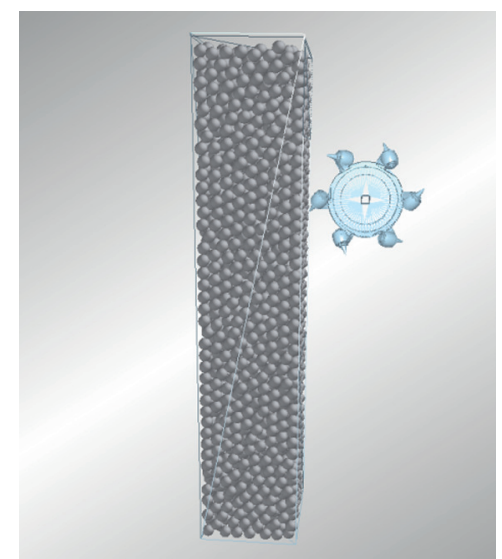

(a)

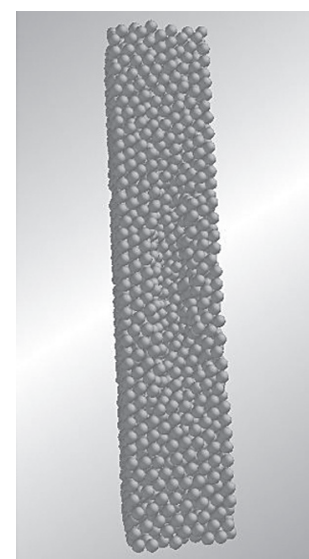

(b)

FIGURE 19: Control group. (a) Coal breaking model. (b) Effect of a certain scheme.

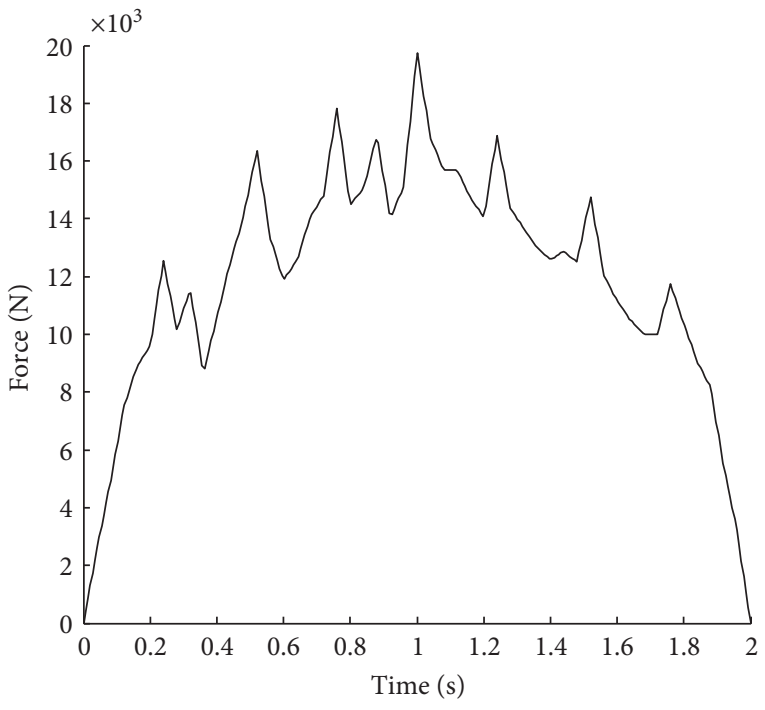

(a)

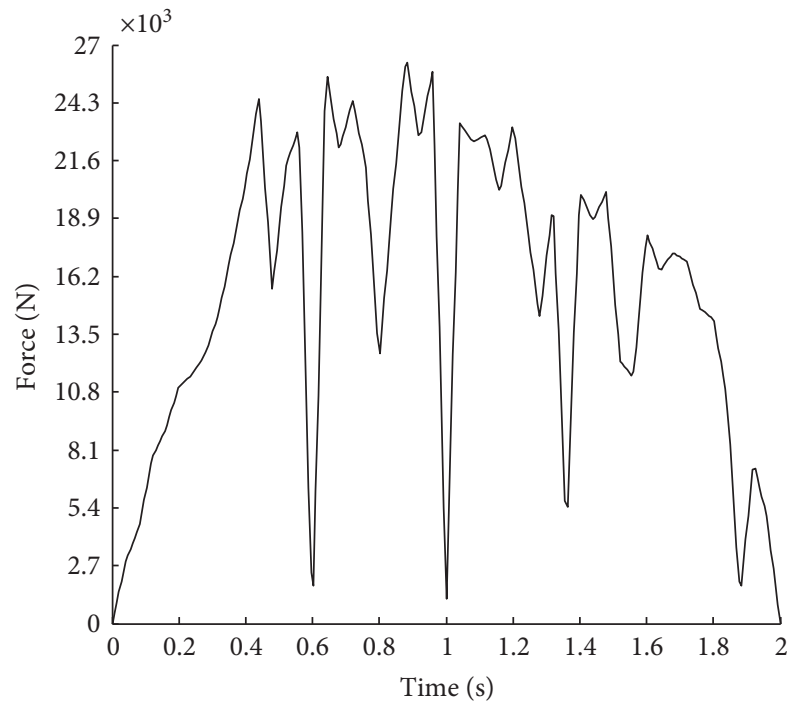

(b)

FIgURE 20: Force of cutting disc for each scheme. (a) With picks impact. (b) Without picks impact.

force of the cutting disc in the impact mode is reduced by $22.47 \%$ compared with the non-impact mode. The crushing effect of impacting-cutting technique for hard coal was verified, and the greater the hardness of coal, the more obvious the advantages of impacting-cutting technique.

\section{Conclusions}

In this study, the impacting-cutting technique was proposed. The impacting-cutting technique drum's crushing properties of hard coal were analyzed by the discrete element simulation method. Meanwhile, the test device of the impactingcutting technique was designed, and the actual coal crushing performance of the impacting-cutting technique was tested. The main conclusions are as follows:

(1) The drum model of the impacting-cutting technique was designed. And the traditional drum and pick structure were modified to enable the picks to perform reciprocating impact motions. The crushing properties of hard coal by the impacting-cutting drum and traditional drum were simulated with the aid of EDEM software.

(2) The simulation results show that the impactingcutting drum has higher coal crushing efficiency, Lower drum force, and more stable cutting processes than the traditional drum. It shows that hard coal might be effectively reduced by the impacting-cutting technique to reduce the difficulty of mining and reflected the applicability in hard coal seams.

(3) A simplified test device for the impacting-cutting technique was designed. And the actual coal crushing performance was tested. The test results show that the force of the cutting mechanism in the impact mode is lower than that of the nonimpact mode, and the force is more stable. It proves that the impacting-cutting technique has a higher 
applicability of hard coal seams than the traditional technique.

\section{Data Availability}

The data used to support the findings of this study are included within the article.

\section{Disclosure}

A preprint of the study has previously been published [24].

\section{Conflicts of Interest}

The authors declare that they have no conflicts of interest regarding the publication of this paper.

\section{Acknowledgments}

The authors gratefully acknowledge the financial support for this work provided by the National Natural Science Foundation of China (Nos. U1810119, 51774161, and 51804151), the Taishan Scholars and Young Experts (No. tsqn201909113), and the Key Project of Shanxi Province Applied Basic Research Plan (No. 201901D111007(ZD)).

\section{References}

[1] T. Li, B. G. Yang, Z. Qi, Q. Shan, and W. Chen, "Numerical simulation of roof movement and fill strength of coal deep mining," Arabian Journal of Geosciences, vol. 14, no. 8, 14 pages, Article ID 665, 2021.

[2] T. Qin, K. Ren, and C. Jiang, "Distribution law of mining stress of the gob-side entry retaining in deep mining thin coal seam," Advances in Civil Engineering, vol. 16, Article ID 5589948, 9 pages, 2021.

[3] S. Justyna and S. Nikodem, "The impact of the coexistence of methane hazard and rock-bursts on the safety of works in underground hard coal mines," Energies, vol. 14, no. 1, 16 pages, Article ID 128, 2021.

[4] Q. Y. Cheng, B. X. Huang, L. Y. Shao, H. Li, and C. Wang, "Combination of pre-pulse and constant pumping rate hydraulic fracturing for weakening hard coal and rock mass," Energies, vol. 13, no. 21, 22 pages, Article ID 5534, 2020.

[5] J. Liu, Y. Xue, Q. Zhang, H. Wang, and S. Wang, "Coupled thermo-hydro-mechanical modelling for geothermal doublet system with 3D fractal fracture," Applied Thermal Engineering, vol. 200, Article ID 117716, 2022.

[6] Y. Xue, J. Liu, P. G. Ranjith, X. Liang, and S. Wang, "Investigation of the influence of gas fracturing on fracturing characteristics of coal mass and gas extraction efficiency based on a multi-physical field model," Journal of Petroleum Science and Engineering, vol. 206, Article ID 109018, 2021.

[7] G. Rehbinder, "Slot cutting in rock with a high speed water jet," International Journal of Rock Mechanics and Mining Science \& Geomechanics Abstracts, vol. 14, no. 5-6, pp. 229234, 2016.

[8] B. Grosso, V. Dentoni, and A. Bortolussi, "Effect of the rock stress on the water jet cutting performance," Rock Mechanics and Rock Engineering, vol. 54, no. 9, pp. 4987-4999, 2021.

[9] F. C. Wang, L. C. Liu, X. Zhou, L. Jie, and G. Chuwen, "New application of abrasive slurry jet in coal rocks breaking and prediction model of its rock breaking ability," Arabian Journal for Science and Engineering, vol. 46, no. 8, pp. 7227-7237, 2021.

[10] S. Liu, Y. Cui, Y. Chen, and C. Guo, "Numerical research on rock breaking by abrasive water jet-pick under confining pressure," International Journal of Rock Mechanics and Mining Sciences, vol. 120, no. 9, pp. 41-49, 2019.

[11] J. L. Chen, Z. H. Jiang, W. F. Han, M. L. Li, and Y. X. Wang, "Breakage mechanism of hard-rock penetration by TBM disc cutter after high pressure water jet precutting," Engineering Fracture Mechanics, vol. 240, no. 3, 17 pages, Article ID 107320, 2020.

[12] F. C. Wang, D. P. Zhou, X. Zhou, N. Xiao, and C. Guo, "Rock breaking performance of TBM disc cutter assisted by highpressure water jet," Applied Sciences, vol. 10, no. 18, 12 pages, Article ID 6294, 2020.

[13] X. Liu, S. Liu, and H. Ji, "Mechanism of rock breaking by pick assisted with water jet of different modes," Journal of Mechanical Science and Technology, vol. 29, no. 12, pp. 53595368, 2015.

[14] Y. J. Zeng, W. H. He, and Z. Zhang, "Rock-breaking performances of innovative triangular-shaped polycrystalline diamond compact cutter," Review of Scientific Instruments, vol. 92, no. 3, 4 pages, Article ID 035115, 2021.

[15] C. S. Liu, Y. Y. Xu, D. G. Li, and H. Yuan, "Mechanical mechanism and model of rock breaking by edge tooth disk," Journal of China Coal Society, vol. 43, no. 1, pp. 272-279, 2018.

[16] A. I. Buikin, A. I. Kamaleeva, and N. A. Migdisova, "Prospects of the method of stepwise crushing as a source of information on the fluid phase of rocks and minerals," Petrology, vol. 24, no. 3, pp. 303-313, 2016.

[17] M. Li, B. Han, Q. Zhang, S. Zhang, and Q. He, "Investigation on rock breaking for sandstone with high power density laser beam," Optik, vol. 180, pp. 635-647, 2019.

[18] J. Zhao, G. Zhang, Y. Xu et al., "Mechanism and effect of jet parameters on particle waterjet rock breaking," Powder Technology, vol. 313, pp. 231-244, 2017.

[19] H. S. Li, S. Y. Liu, Z. C. Zhu, H. Liu, D. Zhang, and C. Guo, "Experimental investigation on rock breaking performance of cutter assisted with hydraulic fracturing," Engineering Fracture Mechanics, vol. 248, no. 2, 12 pages, Article ID 107710, 2021.

[20] J. Chen, L. Guo, and J. Zhang, "Relationship between shock parameter and coal particle parameter of advanced premixed micro-soft abrasive coal-water jet," Powder Technology, vol. 379, pp. 393-406, 2021.

[21] C. S. Liu, D. G. Li, and H. Yuan, "Theoretical mechanical model and load characteristics of coal and rock vibra-tion cutting with disc cutter," Journal of China Coal Society, vol. 45, no. 8, pp. 3015-3023, 2020.

[22] L. Z. Yang, G. J. Wen, and Y. D. Wang, "Theoretical analysis and experimental research on breaking process of laser drilling in coal and rock," Coal Geology \& Exploration, vol. 44, no. 5, pp. 168-172, 2016.

[23] Y. Q. Zuo, K. L. Hui, C. Yi, and H. Zhao, "Fluid-solid coupling analysis on gas path of laser-mechanical combined rock breaking drilling tool," China Petroleum Machinery, vol. 49, no. 9, pp. 1-8, 2021.

[24] Q. Zhang, C. Wang, Y. Tian, and X. Zhang, "Study on working performance of multi-impact drum," Research Square, 2020.

[25] Z.-H. Zhang, F. Min, G.-S. Chen, S.-P. Shen, Z.-C. Wen, and X.-B. Zhou, "Tri-partition state alphabet-based sequential pattern for multivariate time series," Cognitive Computation, 2021.

[26] X. J. Ran, X. B. Zhou, M. Lei, W. Tepsan, and W. Deng, “A novel K-means clustering algorithm with a noise algorithm 
for capturing urban hotspots," Applied Sciences, vol. 11, no. 23, 21 pages, Article ID 11202, 2021.

[27] H. J. Cui, Y. Guan, H. Y. Chen, and W. Deng, "A novel advancing signal processing method based on coupled multistable stochastic resonance for fault detection," Applied Sciences, vol. 11, no. 12, 14 pages, Article ID 5385, 2021.

[28] W. Deng, X. Zhang, Y. Zhou et al., "An enhanced fast nondominated solution sorting genetic algorithm for multi-objective problems," Information Sciences, vol. 585, pp. 441-453, 2022. 